\title{
Topics
}

Robert M. Feinberg*

\section{Pricing of First-Run Movies in Small U.S. Metropolitan Areas: Multimarket Contact and Chain Effects}

\begin{abstract}
In recent years, the role of multimarket contact (MMC) among firms in influencing market performance has been studied for a relatively small group of industries - with banking and airlines most often examined, though the cement and telecommunications industries have been studied as well. This paper investigates this issue for the local movie theater industry in the U.S., one not previously studied in this regard. In small U.S. metropolitan areas, there is considerable variation in the nature of MMC among theater chains (large and small), which allows us to examine whether MMC among firms has an impact on movie pricing in these smaller markets. Data on movie pricing, market structure, and income and population characteristics are obtained for 118 multi-screen first-run movie theaters in 79 small metropolitan areas - those with under 250,000 people - which are not part of larger "consolidated" metropolitan areas. Analysis provides evidence supportive of MMC effects but suggestive of its limited applicability.
\end{abstract}

Keywords: multi-market contact, price determination, movie theaters JEL Codes: L11, L22, L82

\section{Introduction}

Analyzing the potential for market power to be exploited, Industrial Organization economists often consider various "facilitating devices" - features of a market that might tend to encourage tacit or formal collusion. One such feature that has drawn considerable interest in recent years is the role of

*Corresponding author: Robert M. Feinberg, American University, 4400 Massachusetts Ave. N.W., Washington, DC 20016, USA, E-mail: feinber@american.edu 
multimarket contact (MMC) among firms in influencing market performance. However, only a small group of industries has been examined to date. Most prominent in empirical studies are the banking and airline industries (in several countries), though the cement and telecommunications industries have been studied as well. ${ }^{1}$ In addition, early cross-market studies (Scott 1982; Feinberg 1985) found evidence of "mutual forbearance" effects via MMC. Recently, Feinberg (2014) took a preliminary look at this issue for the local movie theater industry, not previously studied in this regard. This paper extends that work further.

While those living in major metropolitan areas of the U.S. generally observe two or more of the large theater chains present, there is much more variation in smaller metropolitan areas in terms of the role of these chains. This allows us to examine whether MMC among firms has an impact on movie pricing in these smaller markets. In this paper, data on movie pricing, market structure, and income and population characteristics are obtained for 118 multi-screen first-run movie theaters in 79 small metropolitan areas. Analysis conducted at the firm (theater) level provides evidence both supportive of MMC effects and suggestive of its limited applicability.

\section{Conceptual framework}

Whether derived from conjectural variations models of oligopoly behavior (Feinberg 1984) or game theoretic approaches (Bernheim and Whinston 1990), the essence of the potential threat posed by MMC to competitive performance is that firms will anticipate that aggressive actions in one market will bring a competitive response not simply in that market but in other markets in which they meet. ${ }^{2}$ In terms of a concept introduced by Feinberg (1985), they will see those "other-market" sales as "sales-at-risk". Of course, what is required for this to make sense is a company structure decentralized enough to make pricing decisions based on local conditions, but centralized enough to look at behavior of competitors elsewhere as well.

Feinberg (1984) proposed a generalized conjectural variations quantity-setting model allowing for MMC among firms leading to each firm anticipating not only the familiar within-market conjectures (whether Cournot, Stackelberg, or

1 For just a few of these, see Heggestad and Rhoades (1978), Evans and Kessides (1994), Jans and Rosenbaum (1997), Parker and Röller (1997), and Ciliberto and Williams (2010).

2 Edwards (1955) is usually thought of as the originator of this idea. 
any other variety) but also a response by rivals across market boundaries. Given these extra-market conjectures, equilibrium output in each market will be closer to the collusive level than if these cross-market conjectures were not present.

Furthermore, as the number of multimarket rivals (and markets) increases, the greater will be the impact on equilibrium output in each market. The term that captures the influence of MMCs on the output decision by a typical firm (say firm A) in market $i$ is $b \sum\left(q_{j} \sum \mathrm{d} q_{j} / \mathrm{d} q_{i}\right)$, where $b$ is a demand parameter, $q_{j}$ is firm A's output in market $j \neq i$ where MMCs exist, $\mathrm{d} q_{j} / \mathrm{d} q_{i}$ is the cross-market conjectural variation by A (assumed to be positive), the first summation is over these $j$ other markets, and the second summation is over rival firms in each of these $j$ markets. The clear implication is that the number of markets where firm A meets other rivals from market $i$, the number of those other rivals, and firm A's output in those markets will matter in its profit-maximizing decision in market $i$.

Bernheim and Whinston (1990), via a repeated multimarket Bertrand game with optimal punishments for deviations from a collusive equilibrium, derive a number of important results. The key issue is the extent to which MMC involves the pooling of incentive constraints across all markets in which the firms meet, potentially relaxing deviation incentives and enhancing the likelihood of collusive behavior being sustained. While MMC does not promote collusion if identical firms meet in identical markets (though experimental results in Feinberg and Sherman (1988) do find this) their results suggest that where market shares, costs, or discount rates (which may proxy growth prospects) differ across firms and markets, MMC may facilitate collusion.

In practice, when are we likely to see MMC significantly affect market performance? In addition to academic interest in the role of MMC, recent discussions of antitrust policy have considered the issue. ${ }^{3}$ The key element would seem to be that "sales-at-risk" in other markets must be large relative to the gains from competitive actions in the market in question (or - what is the same thing - the market in question is relatively small, or unimportant, in the firm's profit calculus). Another consideration is that MMC - which can be considered merely a "facilitating device" in promoting tacit collusion - is not likely to be able to overcome the competition emerging in large markets with large numbers of firms. What seems the most promising scenario to observe an effect is a relatively small market where MMC may be able to cement relationships in avoiding competitive behavior.

3 See, for example, the Antitrust Division's press release explaining its decision to close an investigation of Perdue's acquisition of Coleman Natural Foods (acknowledging the possibility of MMC enhancing coordination in the industry, but dismissing its impact in this case) - http://www.justice.gov/atr/public/press_releases/2011/270591.htm. 
A first step at investigating these issues for movie theaters in small markets is presented in Feinberg (2014). In a sample of 79 small metropolitan areas (all under 250,000 in population), a crude measure of MMC (simply a dummy for at least one such contact elsewhere) is found to raise ticket prices by almost $5 \%$ at the mean sized market (about 150,000), but the effect declines as markets get larger: at the size of the smallest market in the sample the predicted effect is to raise price by over $23 \%$, while at the size of the largest market MMC actually lowers price by $5.75 \%$. Markets under 188,076 in population ( $77 \%$ of the sample) are predicted to experience a rise in price due to MMC.

While Feinberg (2014) hinted at a role for MMC, the simple 0/1 nature of the crucial variable limited the ability to draw more detailed conclusions on the mechanisms by which MMC works on pricing. Furthermore, using the market as unit of observation, firm-level factors were necessarily ignored (including a particular theater's chain affiliation). In what follows, analysis is conducted at the level of the individual theater, allowing for chain fixed effects and for more sophisticated measures of MMC.

\section{Data construction}

Developing an appropriate sample to study the effect of MMC on movie prices, one consideration is that major metropolitan areas in the U.S. generally have at least two of the major movie theater chains present, so there would be little-to-no variation in MMC. At the other extreme, the smallest Census definition - micropolitan areas - tends to have either no movie theaters or only a single independent theater, so again no variation in MMC (simply, no MMC at all). The sample analyzed in this paper is that of movie theaters in metropolitan areas of under 250,000 population (as of 2012 estimates) which are not part of larger "consolidated" metropolitan statistical areas - the 79 such markets in the U.S. range from Lewiston, Idaho (population 61,419) to Binghamton, New York (population 248,538), with the mean population in the sample 149,312 (approximately equal to the population of the Texarkana, Texas metropolitan area). ${ }^{4}$

For each of these markets, I have identified the theaters present (during the first week of November 2013), their chain ownership (if any), market populations

4 Note that this is somewhat different from the mean population reported in Table 1 (which effectively weights market data by the number of firms in each market). 
(for 2012) and per-capita personal income (for 2011), and the non-discounted weekend evening (non-3D) movie price (for Friday evening November 8, 2013). While traditional government sources (Census and BEA) were used for population and income estimates, the primary source of data on numbers and types of movie theaters and ticket prices was the website Fandango.com, supplemented by web searches for situations where Fandango did not report ticket prices and to verify a theater's association with a chain (usually necessary for smaller chains).

Per-capita income, while clearly a demand-side influence on price, is also likely correlated across markets with wage and other movie theater costs - from both perspectives the expectation is a positive effect on price. Market population size is included, both as an indicator of the relative importance of that metropolitan area to chains operating there and as a possible demand-enhancing measure. The number of firms operating in each market is also considered with the usual expectation that more competition should lower prices. As the focus is on independent sources of competition within markets, multiple theaters within a market owned by the same chain or local group were coded as a single theater. ${ }^{5}$ In addition, an arbitrary decision was made that a single-screen theater (usually, but not always, an "art house", showing smaller independent movies) was not a serious competitor in the market, ${ }^{6}$ while those with two or more screens would be included. While, ideally, market structure would be measured by a Herfindahl index or some other indicator of concentration, market share data are not available; this is proxied simply by the number of independent sources of competition (either a chain or a local firm) in the market.

Population and number of firms are included both alone and interacting with MMC. Table 1 presents descriptive statistics. Notice that there is substantial variation across the 118 firms in terms of market population (POP) and per-capita income (INCOME). While there is a reasonable range of ticket prices (PRICE), these cluster quite a bit around the mean of $\$ 9.10$.

The number of firms (NUMBER) goes from 1 to 5, and $28 \%$ of the firms have market rivals they meet elsewhere (MMC). Eight percent of these firms have either just one or two MMCs, and the mean number of MMCs is more than seven. Almost half of these theaters belong to one of the four leading theater chains, while $20 \%$ of them are local independent theaters.

5 Chisholm, McMillan, and Norman (2010) found support for the notion that jointly owned theaters in a market tend to show similar first-run movies.

6 Some support for this assumption is provided by Muller and Bohme (2011). 
Table 1: Descriptive statistics $(n=118)$

\begin{tabular}{lcccc}
\hline & Mean & S.D. & Min & Max \\
\hline PRICE (\$) & 9.10 & 1.19 & 5 & 11.50 \\
POP (000) & 156.8 & 49.3 & 61.4 & 248.5 \\
INCOME (\$000) & 35.9 & 4.9 & 27.1 & 54.1 \\
NUMBER & 1.84 & 0.92 & 1 & 5 \\
MMC (0/1) & 0.28 & 0.45 & 0 & 1 \\
MMC1 & 0.03 & 0.16 & 0 & 1 \\
MMC2 & 0.05 & 0.22 & 0 & 1 \\
MMCover6 & 0.19 & 0.39 & 0 & 1 \\
\#MMCS & 7.42 & 18.75 & 0 & 75 \\
AMC & 0.05 & 0.22 & 0 & 1 \\
CARMIKE & 0.19 & 0.39 & 0 & 1 \\
CINEMARK & 0.09 & 0.29 & 0 & 1 \\
REGAL & 0.14 & 0.34 & 0 & 1 \\
INDEP & 0.20 & 0.40 & 0 & 1 \\
\hline
\end{tabular}

Given the relatively small size of the markets examined here, it is likely that the "other" markets in which these firms meet are larger (and this is certainly true for the smallest of these markets). Therefore, these movie theaters may believe that the small gains they might experience from deviating from tacit collusion here will cost them more in their larger/more-important market interactions.

Below we estimate a reduced-form price equation, with market demand, cost, and market structure proxies included along with several alternative MMC variables. Initially, as in Feinberg (2014), MMC is treated as a 0/1 variable, with a value of one corresponding to a situation where a particular theater meets at least one rival in another metropolitan area. ${ }^{7}$ However, the nature of MMC in these markets varies tremendously; the two chains meeting in Wheeling, WV face each other in just one other market (and similarly for Kahului, HI), while the third and fourth leading chains - Cinemark and Carmike - operating in Wichita Falls, TX compete in more than 25 other geographic markets and the two leading chains - AMC and Regal, operating in Binghamton, NY, and CrestviewFt. Walton Beach, Destin, FL - meet in far more markets. We deal with this in two ways, first via a continuous measure of MMCs and then with several dummy variables.

7 An alternative definition would have MMC $=1$ where any two firms in the market meet elsewhere, but that variable is almost perfectly correlated with the firm-level measure $(+0.96)$ and - not surprisingly - results are robust to which of these measures is used. 


\section{Results}

The econometric approach is quite simple, using OLS with robust standard errors. The movie ticket price is estimated as a function of market size, percapita income, the number of firms in the market, and (as a first step) the indicator variable for MMC. All continuous variables - PRICE, POP, and INCOME - are expressed in natural logs; this implies that the effect of the dummy variable MMC can be seen as a percentage change in price due to the possibility of mutual forbearance behavior. ${ }^{8}$ The unit of observation is a particular theater in one of the 79 small Metropolitan Statistical Areas.

Table 2 presents the initial results, In column (1), we see that theaters in higher-income markets have higher movie ticket prices (as anticipated, viewing per-capita income either as a demand-side or as a cost-side proxy), and those in markets with more competition charge lower prices - both of these estimated effects are significant at $1 \%$. There is no significant impact of market size or of MMC. ${ }^{9}$ As noted earlier, the intuition of the mutual forbearance hypothesis resulting from MMC is that this is more likely to follow as other markets - and the sales "at-risk" in those - are more important. Operationalizing that, we introduce an interaction term between MMC and lnPOP, with results in column (2); we now find, as expected, both MMC and the interaction term to be statistically significant (though only at 10\%) suggesting a large positive impact of MMC on PRICE in the smallest markets, with the effect diminishing as markets increase in size, while income and number of firms continue to have statistically significant impacts with the expected signs.

At the mean market size for our sample, the estimated impact of MMC is to raise ticket prices by $2.8 \%$, but the implications for extremes of population are quite different: at 61,419 (the smallest market in the sample) the predicted effect is to raise PRICE by $21.5 \%$, while at 248,538 (the largest market in the sample) MMC actually lowers price by $6.3 \%{ }^{10}$ Theaters in markets under 180,869 in population (68\% of the sample) are predicted to increase price due to MMC.

Given the reduced-form nature of the price equation estimated, endogeneity concerns must be addressed. In particular, market structure (here proxied by

8 The results with all variables in levels are quite similar.

9 Davis (2005) found a significant but small impact of local market structure on movie prices in a study of large U.S. markets in the mid-1990s. Bohme and Muller (2011) found no significant difference in movie theater pricing between monopoly and oligopoly markets in Germany.

10 While this price-reducing impact of MMC for larger markets may simply be an artifact of our econometric specification (and in future work, one might restrict effects to be non-negative), there has been some work (one recent example is Arie, Markovich, and Varela (2014)) suggesting that - in some cases - MMC can allow cost efficiencies across markets. 
Table 2: Regression results, MMC dummy variable

\begin{tabular}{|c|c|c|c|}
\hline & \multicolumn{3}{|c|}{ Estimated coefficients } \\
\hline & (1) & (2) & (3) \\
\hline \multirow[t]{2}{*}{ Constant } & -1.539 & $-1.905^{\star}$ & -1.007 \\
\hline & (1.058) & (1.109) & $(0.951)$ \\
\hline \multirow[t]{2}{*}{$\ln \mathrm{POP}$} & 0.032 & 0.067 & $0.071^{\star}$ \\
\hline & $(0.042)$ & $(0.044)$ & $(0.039)$ \\
\hline \multirow[t]{2}{*}{ InINCOME } & $0.326^{\star \star \star}$ & $0.323^{\star \star \star}$ & $0.228^{\star \star \star}$ \\
\hline & $(0.101)$ & $(0.101)$ & $(0.084)$ \\
\hline \multirow[t]{2}{*}{ NUMBER } & $-0.038^{\star \star \star}$ & $-0.040^{\star \star \star}$ & $-0.021^{\star}$ \\
\hline & $(0.011)$ & $(0.011)$ & $(0.012)$ \\
\hline \multirow[t]{2}{*}{ MMC } & 0.009 & $2.409^{\star}$ & $2.778^{\star \star}$ \\
\hline & $(0.034)$ & $(1.021)$ & $(1.159)$ \\
\hline \multirow[t]{2}{*}{$M M C^{\star} \ln P O P$} & - & $-0.199^{\star}$ & $-0.234^{\star \star}$ \\
\hline & & $(0.109)$ & $(0.096)$ \\
\hline \multirow[t]{2}{*}{ AMC } & - & - & $0.123^{\star \star \star}$ \\
\hline & & $(0.037)$ & \\
\hline \multirow[t]{2}{*}{ CARMIKE } & - & - & $0.079 * \star$ \\
\hline & & $(0.033)$ & \\
\hline \multirow[t]{2}{*}{ CINEMARK } & - & - & -0.022 \\
\hline & & $(0.038)$ & \\
\hline \multirow[t]{2}{*}{ REGAL } & - & - & $0.127^{\star \star \star}$ \\
\hline & & $(0.035)$ & \\
\hline \multirow[t]{2}{*}{ INDEP } & - & - & $-0.075^{\star \star}$ \\
\hline & & (0.038) & \\
\hline$R^{2}$ & 0.131 & 0.157 & 0.356 \\
\hline
\end{tabular}

Notes: Robust standard errors are in parentheses below estimated coefficients. ${ }^{* \star \star}$ Significance at $1 \%$. ${ }^{\star \star}$ Significance at $5 \%$. ${ }^{\star}$ Significance at $10 \%$. Dependent Variable $=\operatorname{InPRICE}(n=118)$.

number of firms in the market) may be related to local prices ${ }^{11}$; it may also be viewed as determined by market size (along the lines of Bresnahan and Reiss (1991)). Estimates for the column (2) specification were obtained instrumenting for number of firms (using the prevalence of broadband internet service in the market at the time period in question as an instrument in a first-stage equation); the effects of MMC were not impacted in an important way.

11 This is not, however, expected to be a problem here - given the time lags involved in entering a market (either de novo or through acquisition of an existing theater), one would not expect to see much impact of current prices on the number of firms present in the market. 
While coordinated chain pricing across markets may imply MMC impacts, there may also be possible fixed effects. ${ }^{12}$ We create dummy variables for a theater's membership in one of the four largest theater chains - AMC, Carmike, Cinemark, and Regal - as well as for a purely local/independent ownership, ${ }^{13}$ and include these in the specification of column (3). Results are similar to those of column (2), however the estimated effects of MMC - both on its own and interacted with population - are now significant at 5\%. And we do find that the two largest chains - Regal and AMC - each seems to price about 12.5\% higher than the excluded group (small, regional chains) while the fourth leading chain, Carmike prices about $8 \%$ higher. There is no significant effect for the third leading chain, Cinemark. Locally owned theaters price about 7.5\% lower than the excluded group. ${ }^{14}$

While these results suggest an impact of MMC, we now examine variations in the importance of such contacts. First, instead of treating it as a $0 / 1$ variable, the actual number of other markets in which the firms in a particular market meet is calculated - given some MMC, this varies from 1 to $75 .{ }^{15}$ In addition, theory suggests that MMC may have a larger price effect in markets where tacit collusion is more difficult to achieve in its absence, as the number of firms increases. In Table 3 , results are presented with $\ln (\# M M C s)^{16}$ included as an explanatory variable - interacted with both the number of firms and the log of market population size. We continue to see the income and chain effects found in Table 2. And both interaction terms with $\ln (\# M M C s)$ are statistically significant,

12 For MMC to play a role we require a balancing of nation-wide pricing by chains and focus on local competitive concerns. Within theaters owned by each of the four leading chains, we do see considerable variation in prices (though not quite as large as that found in the complete sample of theaters). For example, prices range from $\$ 8.75$ to $\$ 10.25$ for AMC, from $\$ 7.25$ to $\$ 10.75$ for Carmike, from $\$ 6.25$ to $\$ 9.50$ for Cinemark, and from $\$ 7.00$ to $\$ 11.50$ for Regal.

13 The omitted group here contains the large number of small, mostly regional, movie chains found in these small markets.

14 Interpreting these chain (and independent) fixed effects is not clear-cut, as they may reflect in part fixed effects of the markets in which they operate. The higher major-chain effects may also reflect theater quality.

15 For most observations multimarket contacts were determined in terms of meetings of theaters usually within 10 miles of one another (some exceptions where they were somewhat further apart but clearly within a 20-30 min drive of one another); the highest value was 53 extra-market meetings between Carmike (the fourth leading chain) and Regal (the top chain). Market definition becomes more difficult for theater chains present in virtually all major U.S. markets, especially in consolidated metropolitan statistical areas which comprise a fairly large geographical area. For these extra-market meetings between Cinemark (\#3) and Regal, an estimated value of 60 was chosen; for those between Regal and AMC (\#2), an estimated value of 75 was used. Results are not sensitive to variation in these imputed figures.

16 As there are many zero observations of \#MMCs, what actually calculated is $\ln$ (\#MMCs $+0.1)$. 
Table 3: Regression results, examining MMC numbers (continuous variable)

\begin{tabular}{|c|c|}
\hline Constant & $\begin{array}{r}0.802 \\
(1.071)\end{array}$ \\
\hline $\ln \mathrm{POP}$ & $\begin{array}{l}-0.077 \\
(0.060)\end{array}$ \\
\hline InINCOME & $\begin{array}{c}0.212^{\star \star} \\
(0.083)\end{array}$ \\
\hline NUMBER & $\begin{array}{r}0.029 \\
(0.024)\end{array}$ \\
\hline $\ln (\# M M C s)$ & $\begin{array}{l}0.694^{\star \star} \\
(0.306)\end{array}$ \\
\hline $\ln (\# M M C s) \star \ln P O P$ & $\begin{array}{l}-0.063^{\star \star} \\
(0.026)\end{array}$ \\
\hline $\ln (\# M M C S) \star N U M B E R$ & $\begin{array}{c}0.025^{\star \star} \\
(0.010)\end{array}$ \\
\hline AMC & $\begin{array}{l}0.116^{\star \star \star \star} \\
(0.036)\end{array}$ \\
\hline CARMIKE & $\begin{array}{l}0.086^{\star * *} \\
(0.033)\end{array}$ \\
\hline CINEMARK & $\begin{array}{l}-0.009 \\
(0.037)\end{array}$ \\
\hline REGAL & $\begin{array}{l}0.129^{\star \star *} \\
(0.033)\end{array}$ \\
\hline INDEP & $\begin{array}{l}-0.067^{\star} \\
(0.039)\end{array}$ \\
\hline$R^{2}$ & 0.383 \\
\hline
\end{tabular}

Notes: Robust standard errors are in parentheses below estimated coefficients. ${ }^{* *}$ Significance at $1 \%,{ }^{*}$ Significance at $5 \%,{ }^{\star}$ Significance at $10 \%$. Dependent variable $=\operatorname{lnPRICE}$ $(n=118)$.

suggesting (as before) not only that smaller markets are more likely to see priceincreasing effects of MMC but also that magnitudes of these effects are larger as the number of independent sources of competition in a market increases. At the mean population size of 150,000 , the elasticity of price with respect to an extra MMC is virtually zero for two-firm markets, 0.018 for three-firm markets, 0.043 for four4-firm markets, and 0.078 for five-firm markets.

In Table 4, we consider that the impact of the number of MMCs may not be continuous. One might think that once the number of these extra-market contacts gets beyond a small number, additional contacts may not matter in a firm's pricing decision. Here we create three dummy variables for $\# M M C s=1(\mathrm{MMC1}),=2$ 
Table 4: Regression results, MMC numbers in ranges

\begin{tabular}{ll}
\hline Constant & -0.694 \\
InPOP & $(0.883)$ \\
& $0.072^{\star}$ \\
InINCOME & $(0.039)$ \\
& $0.198^{\star \star}$ \\
NUMBER & $(0.077)$ \\
& -0.027 \\
MMCover6 & $(0.012)$ \\
MMC1*InPOP & $4.114^{\star \star}$ \\
& $(1.730)$ \\
MMC2*InPOP & -0.022 \\
& $(0.568)$ \\
MMCover6*InPOP & 0.077 \\
MMC1*NUMBER & $(0.247)$ \\
& $-0.364^{\star \star}$ \\
MMC2*NUMBER & $(0.150)$ \\
& 0.159 \\
MMCover6*NUMBER & $(3.386)$ \\
AMC & -0.545 \\
CARMIKE & $(1.487)$ \\
CINEMARK & $0.107^{\star}$ \\
REGAL & $(0.060)$ \\
& $0.107^{\star \star \star}$ \\
& $(0.035)$ \\
& $0.082^{\star \star \star}$ \\
& $(0.031)$ \\
& -0.015 \\
& $(0.037)$ \\
& $0.121^{\star \star \star}$ \\
& $(0.032)$ \\
& $-0.075^{\star}$ \\
& $(0.038)$ \\
& 0.424 \\
\hline
\end{tabular}

Notes: Robust standard errors are in parentheses below estimated coefficients. ${ }^{* \star}$ Significance at $1 \%,{ }^{*}$ Significance at $5 \%$,

*Significance at $10 \%$. Dependent variable $=\operatorname{InPRICE}(n=118)$.

(MMC2), and greater than 6 (MMCHIGH) ${ }^{17}$ and include them on their own ${ }^{18}$ and interacted with numbers of firms and the log of market population. Income and

17 There were no observations of \#MMCs between 2 and 7.

18 MMC1 and MMC2 were each perfectly correlated with the number of firms (NUMBER) interacted with MMC1 and MMC2, respectively, so were dropped from the regression equation. 
population have positive effects on movie prices, and the chain dummy variables continue to have the effects noted above. It appears that the impact of MMC on pricing is driven by the instances of frequent MMC, as MMC1 and MMC2 have no significant impact on price, but both interaction terms of MMCHIGH are statistically significant with signs as expected. At the mean population size, having more than six MMCs is estimated to raise ticket prices by $9.6 \%$ in three-firm markets, by $20 \%$ in four-firm markets, and 31\% in five-firm markets.

\section{Conclusions}

The results presented here are consistent with the view that MMC among firms can help facilitate tacit collusion and point to some guidance as to when this is most likely. We are most likely to see these effects in moderately concentrated markets which are small enough that gains from competitive moves are outweighed by possible retaliatory actions addressed elsewhere; highly concentrated markets probably do not need MMC to coordinate pricing, while those with very low levels of concentration are unlikely to be aided toward tacit collusion by MMC. Furthermore, a substantial amount of contacts in other markets seems to be required for price-increasing effects to be observed.

Where markets meet these conditions one should keep MMC in mind in evaluating the potential exercise of market power. In particular, industries characterized by local geographic markets may be candidates for this factor to play a significant role, especially where national chains are present in some, but not all, of these markets. But even here, only where the number of local firms is neither very large nor very small would we expect MMC to be of great importance.

Acknowledgments: I thank Wally Mullin and an anonymous referee for comments on earlier drafts of this paper. No financial support was received in connection with this research.

\section{References}

Arie, G., S. Markovich, and M. Varela. 2014. "The Competitive Effect of Multimarket Contact." Simon School Working Paper No. FR 12-12.

Bernheim, B. D., and M. D. Whinston. 1990. "Multimarket Contact and Collusive Behavior." Rand Journal of Economics 21:1-26.

Bresnahan, T. F., and P. C. Reiss. 1991. "Entry and Competition in Concentrated Markets." Journal of Political Economy 99(5):977-1009. 
Chisholm, D. C., M. S. McMillan, and G. Norman. 2010. "Product Differentiation and Film-Programming Choice: Do First-Run Movie Theatres Show the Same Films?" Journal of Cultural Economics 34(2):131-45.

Ciliberto, F., and J. W. Williams. 2010. "Does Multimarket Contact Facilitate Tacit Collusion? Inference on Conduct Parameters in the Airline Industry." Working Paper.

Davis, P. 2005. "The Effect of Local Competition on Admission Prices in the U.S. Motion Picture Exhibition Market." Journal of Law and Economics 48:677-707.

Edwards, C. D. 1955. "Conglomerate Bigness as a Source of Power." In Business Concentration and Price Policy (NBER Conference Report), 331-52. Princeton, N): Princeton University Press.

Bohme, M., and C. Muller. 2011. "Searching for the Concentration-Price Effect in the German Movie Theater Industry." Jahrbucher fur Nationalokonomie und Statistik 231(4):479-93.

Evans, W. N., and I. N. Kessides. 1994. "Living by the 'Golden Rule': Multimarket Contact in the U.S. Airline Industry.” Quarterly Journal of Economics 109(2):341-66.

Feinberg, R. M. 1984. "Mutual Forbearance as an Extension of Oligopoly Theory." Journal of Economics and Business 36:242-49.

Feinberg, R. M. 1985. “'Sales-at-Risk': A Test of the Mutual Forbearance Theory of Conglomerate Behavior." Journal of Business 58(2):225-41.

Feinberg, R. M. 2014. "Price Effects of Multimarket Contact Among Movie Chains in Small U.S. Metropolitan Areas." Economics Letters 123(1):6-8.

Feinberg, R. M., and R. Sherman. 1988. "Mutual Forbearance under Experimental Conditions." Southern Economic Journal 54:985-93.

Heggestad, A., and S. A. Rhoades. 1978. "Multi-Market Interdependence and Local Market Competition in Banking." Review of Economics and Statistics 60:523-32.

Jans, I., and D. I. Rosenbaum. 1997. "Multimarket Contact and Pricing: Evidence from the U.S. Cement Industry." International Journal of Industrial Organization 15(3):391-412.

Muller, C., and E. Bohme. 2011. "A Note on the Relationship of Mainstream and Art House Movie Theaters.” Economics Bulletin 31(1):29-34.

Parker, P. M., and L.-H. Röller. 1997. "Collusive Conduct in Duopolies: Multimarket Contact and Cross-Ownership in the Mobile Telephone Industry." RAND Journal of Economics 28(2):304-22.

Scott, J. T. 1982. "Multimarket Contact and Economic Performance." Review of Economics and Statistics 64:368-75. 